\title{
Why psychologists do not want to work with older adults - and why they should...
}

It is well-documented that the population of much of the developed world is aging. On the one hand, this represents a success story in terms of reducing deaths from infectious and a number of systemic diseases, most notably cardiovascular disease. On the other hand, it also presents a challenge to provide adequate health services to a population with rapidly increasing longevity, as well as an opportunity to develop policies that can assist in promoting good physical and mental health. A number of authors have asked whether we are ready to meet the challenges of an aging population (Doyle et al., 2009; Connolly, 2012). Over the years, prominent psychologists have suggested that clinical psychology could play a greater role in the provision of services for older adults, and lamented the apparent lack of enthusiasm on the part of psychologists to work with this group (e.g. Karel et al., 2012). In this paper, we examine a range of questions pertinent to this theme: where are the psychologists in the provision of mental health services to older adults? What contribution can psychologists make to improve the mental health of this growing sector of the population? How can we encourage more psychologists to specialize in working with older adults?

\section{Is it the case that psychologists do not want to work with older adults?}

First, we need to consider whether it is actually the case that psychologists do not regard older adults as a desirable population to work with. The findings of a number of studies appear to confirm that this is the case. For example, in a Portuguese study of 460 undergraduate students, psychology students not only rated lowest in terms of scores on a questionnaire measuring attitude towards older adults compared to the other professional groups, (nursing and social work trainees), but also rated older adults as the lowest in work interest ratings compared to adolescents and younger adults (Goncalves et al., 2011). The fear that this may translate into few psychologists being available to provide much needed services is a real one, reflected in figures such as the 2008 American Psychological Association Survey of Psychology Health Service Providers, which found that only $4.2 \%$ of psychologists listed older adults as their main area of clinical service (APA Center for Workforce Studies, 2008 reported in American Psychological Association, 2014). Similar figures were obtained from an Australian survey, in which $6 \%$ of psychologists surveyed indicated that they were specialists in aged care, with $40 \%$ of the sample indicating they had no contact with older clients (Koder and Helmes, 2008a). UK figures are also comparable, with an international trend towards low resources for older people requiring psychological services.

Investigations into reasons for this low level of psychologist interest have suggested the importance of a number of factors, starting with professional ageism. From the time of Freud, there have been negative views regarding the potential of the older person to benefit from psychological therapies that are seen to require flexibility of thinking: '... near or above the fifties the elasticity of mental processes on which the treatment depends, is as a rule lacking... old people are no longer educable' (Freud, 1905, in Murphy, 2000, p.182). He was 49 years old at the time of writing this quote. As a consequence of lack of interest in working with older adults, therapeutic nihilism negatively impacts on older adults' access to potentially efficacious psychological interventions (Hepple, 2004). A wide range of ageist views have been quoted in several studies, for example: 'feeling that older people's lives, filled with bereavement, failing faculties and limited opportunities, are inherently depressing-so what can one do?' (Lee et al., 2003, p. 5). An Israeli survey reported that $55 \%$ of their sample of clinical psychologists indicated they specifically did not want to work with older clients (Shmotkin et al., 1992).

Other factors predicting whether a psychologist specializes in aged care are contact, training and knowledge (Koder and Helmes, 2008b). Studies examining all three of these factors suggest that level of training has the most influence (Koder and Helmes, 2008b). Clinical exposure is of particular importance in mediating interest 
(Karel et al., 2012). One key mechanism may well be the challenging of pre-existing negative stereotypes regarding older adults through positive, supportive clinical experiences. However, a recent international survey indicated a lack of significant growth in geropsychology training with only $28.3 \%$ of U.S. graduate programs offering courses on geropsychology (Pachana et al., 2010). Initiatives such as the development of the Pikes Peak model for geropsychology training in the U.S (Knight et al., 2009) provide an outline of core attitudes, knowledge and skill competencies for working with older adults. Similar efforts to develop guidelines for training psychologists for work with older adults have been taken place in the U.K. and Australia (Pachana et al., 2006). Promoting quality internship experiences in aged care settings is highly recommended, but the dearth of suitably experienced supervisors and the optional nature of aged care specific placements in some countries such as Australia is a barrier to this goal (Pachana et al., 2010).

\section{What role can psychologists play in promoting the mental health of older adults?}

The lack of interest and high quality training experiences might not matter if it were the case that psychology interventions had little to offer the older client. To illustrate that this is not so, we present examples of evidence-based treatments from three clinical domains. First, increasing age is a risk factor for the development of neurocognitive disorders, a group of syndromes with diverse etiologies. They have in common a progressive nature, and a strong association with behavioral disturbances that are distressing to both the person with the disorder, and their carers (Cohen-Mansfield, 2013). Drug treatments appear to be of limited value in this context, and carry the danger of side-effects (Ouslander et al., 2003). A number of effective interventions have been developed in order to help carers cope with the burden of caring for a person with dementia, and, in some cases, delay admission to residential care (Elvish et al., 2013). These interventions typically incorporate elements of psychoeducation, teaching skills in behavior management, and providing support and advice to the carers. The training of psychologists in understanding and managing behavior places them ideally to provide this type of clinical intervention. Similar principles can be applied in residential care settings, where challenging behaviors occur frequently.

Second, with longer life expectancy comes more years of living with chronic health conditions.
Some of these are associated with chronic pain, which patients experience as frustrating and limiting, and clinicians can find challenging to treat. A recent randomized controlled trial (RCT) compared two psychological interventions (cognitive behavior therapy (CBT) and acceptance and commitment therapy (ACT)) for chronic pain in a group of 114 participants, of whom $18 \%$ were over the age of 65 years (Wetherell et al., 2011). Both treatments resulted in reductions in pain interference, depression, and pain-related anxiety, with no significant differences between the two interventions, but ACT was perceived to be a more acceptable therapy, resulting in fewer drop outs. This highlights the role that psychological intervention can play in the management of chronic health conditions, in order to increase quality of life and functioning in older adults.

Third, depression has been termed the 'common cold' of the psyche (Seligman, 1975), and prevalence amongst older adults is high, particularly in residential care settings (Snowdon and Fleming, 2008). With older males over-represented in suicide population figures (Australian Bureau of Statistics, 2014), timely detection and treatment is essential. Psychologists are well-placed to conduct psychotherapy for the management of disorders such as depression and anxiety, with strong support from the research literature (for example, Frazer, et al., 2005; Cuijpers et al., 2006). Several group programs have been described that adapt cognitive behavioral approaches to treat depression in residential settings (for example, The BE-ACTIV program of Meeks et al., 2008).

Two other points are worth noting. First, the current cohort of older adults may be reluctant to seek psychological help, which can be seen as stigmatizing and a sign of weakness (Zarit and Zarit, 2006). The baby-boomers, who are now reaching old age, have grown up in an era of greater psychological awareness, and are likely to make stronger demands for psychological intervention (Laidlaw, 2013). In light of the reluctance on the part of the psychologists to work with older adults, it is possible that there will not be a workforce that is adequately trained to respond to their needs. Secondly, as healthcare becomes more complex, the need for cross-disciplinary co-operation becomes increasingly important (Karel et al., 2012). Patientcentered care requires an integrated approach to meet the psychological and physical needs of the aging population, yet psychologists remain underrepresented in the physical healthcare setting, and 'notably absent from policy analyses of geriatric workforce needs' (Karel et al., 2012, p. 187). 


\section{How can we encourage more psychologists to specialize in working with older adults?}

We suggest that there are a number of ways to increase the contribution that psychologists could make to the well-being of older adults. These need to approach the challenge from a number of different angles. First, there is strong evidence that training has the greatest influence on fostering an interest in working with older adults, highlighting the importance of interventions at this level (Koder and Helmes, 2008b). At the undergraduate psychology degree level, courses typically contain very little content on ageing. 'Developmental psychology' is often presented with a heavy focus on childhood and adolescence and relative neglect of old age, a period in the lifespan that can occupy 30 years or more. Even at the clinical psychology training level, this bias continues. Moreover, an excessive focus on assessment and diagnosis at the expense of courses that teach practical skills in therapy and crossdisciplinary collaboration may also bias the trainee against working with older adults (Pachana et al., 2010). Until recently, it was mandatory in the United Kingdom for clinical psychology trainees to undertake a placement in an old age service. This would be highly desirable, as it appears that clinical exposure to work with older clients is more effective in inspiring trainees than lectures and coursework (Koder and Helmes, 2008c). This is consistent with theories of stereotype formation and maintenance that suggest that exposure to counter-stereotypical information is the most powerful form of stereotype challenge (Vaughan and Hogg, 2005). In the clinical context, this could lead the student's realization that older adults are interesting, retain a sense of humor, and have the flexibility to adopt new behaviors.

Secondly, there is much room for increasing awareness of the role of the psychologist among the other professionals involved in the care of older people, thereby improving access to psychological intervention. Psychologists need to work closely with primary care providers in providing both education and early intervention regarding the ability of older adults to benefit from psychological techniques. One of the authors (CB) recalls a client who experienced severe fear of falling, and had been told by her G.P. that there was 'no treatment for your condition'. In addition, psychologists can be representatives on local health advisory boards, develop private practice partnerships within existing primary care physician or geriatrician clinical practices, and be part of regular multidisciplinary professional development networks to promote their role. It may also be useful to emphasize that the role of the clinical psychologist is not restricted to treatment of mental illness, but can also encompass the potentially less stigmatizing roles of support and guidance in relation to normative experiences, such as retirement planning, and adapting to caring responsibilities.

At the policy level, much could be done to increase access to psychological services. For example, currently in Australia, residents of residential care homes are not able to access rebated clinical psychology services, but must either access already over-stretched public mental health teams, or fund their treatment privately. More broadly, attitudes towards working with older adults are intrinsically connected to attitudes towards ageing itself. It is hard to see how a greater readiness amongst psychologists to work with older adults can develop in the absence of a fundamental shift away from stereotyped images of ageing.

In this $25^{\text {th }}$ anniversary year of International Psychogeriatrics, it is worth reflecting on progress towards the goal of 'Better Mental Health for Older People'. On the one hand, the last 25 years have witnessed a huge growth in the contribution that psychologists are making to research on aging. On the other hand, psychologists still lag behind in our clinical contribution to the mental health of older people, particularly in the therapy and counseling domains. As long ago as 1977, Maizler and Ronch stated that 'The question today is not so much whether "older people are no longer educable", but whether we, the professionals are.' (Maizler and Ronch, 1977, p. 283). Perhaps it will be older people themselves who finally educate us and prompt us to rise to the challenge: the baby-boomers are adopting different attitudes towards their own aging, and are likely to demand more psychologically-focused interventions. Clinical psychologists have much to offer, but have, as yet, not fulfilled that potential. We have argued that creating more opportunities to work with older adults during clinical psychology training, being more active in clinical and policy debates and working actively within the broader discourse about ageing to promote the psychological needs of older adults may help us to be prepared to meet the demand that future years will bring.

\section{Conflict of interest}

None.

\footnotetext{
CHRISTINA BRYANT ${ }^{1,2}$ AND DEBORAH KODER ${ }^{3}$

${ }^{1}$ Melbourne School of Psychological Sciences, University of Melbourne, Melbourne, Victoria, Australia ${ }^{2}$ Centre for Women's Mental Health, Royal Women's Hospital, Parkville, Victoria, Australia
} 
${ }^{3}$ Mental Health Service for Older People, Sydney Local Health District, Royal Prince Alfred Hospital, Sydney, Australia

\section{References}

American Psychological Association (2014). Guidelines for psychological practice with older adults. American Psychologist, 69, 35-65.

Australian Bureau of Statistics (2014). Causes of Death, Australia, 2012. Catalogue No. 3303.0. Belconnen, ACT: Commonwealth of Australia.

British Psychological Society (2006). Specialists working with older people. Good Practice Guidelines of UK Clinical Psychology Training Providers for the Training and Consolidation of Clinical Practice in Relation to Older People. Leicester: British Psychological Society.

Cohen-Mansfield, J. (2013). Nonpharmacologic treatment of behavioral disorders in dementia. Current Treatment Options in Neurology, 15, 765-785.

Connolly, M. (2012). Futurology and mental health services: are we ready for the demographic transition? The Psychiatrist, 36, 161-164.

Cuijpers, P., Van Straten, A. and Smit, F. (2006). Psychological treatment of late-life depression: a meta-anlysis of randomized controlled trials. International journal of Geriatric Psychiatry, 21, 1139-1620

Doyle, Y., McKee, M., Rechel, B. and Grundy, E. (2009). Meeting the challenge of population aging. British Medical fournal, 339, 892-894.

Elvish, R., Lever, SJ, Johnstone, J., Cawley, R. and Keady, J. (2013). Psychological interventions for carers of people with dementia: a systematic review of quantitative and qualitative evidence. Counselling and Psychotherapy Research, 13, 106-125

Frazer, C., Christensen, H. and Griffiths, K. (2005). Effectiveness of treatment for depression in older people. Medical Fournal of Australia, 182, 627-632.

Goncalves, D. et al. (2011). Attitudes, knowledge and interest: preparing university students to work in an aging world. International Psychogeriatrics, 23, 315-321.

Hepple, J. (2004). Psychotherapies with older people: an overview. Advances in Psychiatric Treatment, 10, 371-377.

Karel, M., Gatz, M. and Smyer, M. (2012). Aging and mental health in the decade ahead: what psychologists need to know. American Psychologist, 67, 184-198.

Knight, B., Karel, M., Hinrichsen, G., Qualls, S. and Duffy, M. (2009). Pikes Peak model for training in professional geropsychology. American Psychologist, 64, 205-214.

Koder, D. and Helmes, E. (2008a). The current status of clinical geropsychology in Australia: a survey of practising psychologists. Australian Psychologist, 43, 22-26.
Koder, D. and Helmes, E. (2008b). Predictors of working with older adults in an Australian psychologist sample: revisiting the influence of contact. Professional Psychology: Research and Practice, 39, 276-282

Koder, D. and Helmes, E. (2008c). Predictors of interest in working with older adults: a survey of post-graduate trainee psychologists. Gerontology and Geriatrics Education, 29, 158-171.

Laidlaw, K. (2013). A deficit in psychotherapeutic care for older people with depression and anxiety. Gerontology, 59, 549-556.

Lee, K., Volans, J. and Gregory, N. (2003). Trainee clinical psychologists' views on recruitment to work with older people. Aging and Society, 22, 1-15.

Maizler, J. and Ronch, , (1977), Individual psychotherapy with the institutionalized aged. American fournal of Orthopsychiatry, 47, 275-283.

Meeks, S., Looney, S., Van Haitsma, K. and Teri, L. (2008). BE-ACTIV: a staff-assisted behavioural intervention for depression in nursing homes. Gerontologist, $48,105-114$.

Murphy, S. (2000). Provision of psychotherapy services for older people. Psychiatric Bulletin, 24, 181-184.

Ouslander, J., Bartels, S., Beck, C., Beecham, N., Burger, S. and Clark, T. (2003). Consensus statement on improving the quality of mental healthcare in US nursing homes: management of depression and behavioral symptoms associated with dementia. Fournal of the American Geriatric Society, 51, 1287-98.

Pachana, N., Emery, E., Konnert, C., Woodhead, E. and Edelstein, B. (2010). Geropsychology content in clinical training programs: a comparison of Australian, Canadian and US data. International Psychogeriatrics, 22, 909918.

Pachana, N., Helmes, E. and Koder, D. (2006). Guidelines for the provision of psychological services for older adults. Australian Psychologist, 41, 15-22.

Seligman, M. (1975). Helplessness: on Depression, Development, and Death. San Francisco: W.H. Freeman.

Shmotkin, D., Eyal, N. and Lomranz, J. (1992). Motivations and attitudes of clinical psychologists regarding treatment of the elderly. Educational Gerontology, 18, 177-192.

Snowdon, J. and Fleming, R. (2008). Recognizing depression in residential facilitites: an Australian challenge. International Fournal of Geriatric Psychiatry, 23, 295-300

Vaughn, G. M. and Hogg, M. A. (2005). Introduction to Social Psychology, $4^{\text {th }}$ edn. Sydney: Pearson.

Wetherell, J. L. et al. (2011). A randomized, controlled trial of acceptance and commitment therapy and cognitive-behavioral therapy for chronic pain. Pain, 152, 2098-2107.

Zarit, S. and Zarit, J. (2006). Mental disorders in older adults: fundamentals of assessment and treatment. New York: The Guilford Press. 